\title{
Preoperative Chemoradiotherapy Does Not Necessarily Reduce Lymph Node Retrieval in Rectal Cancer Specimens-Results from a Prospective Evaluation with Extensive Pathological Work-up
}

\author{
Thilo Sprenger • Hilka Rothe $\cdot$ Kia Homayounfar • \\ Tim Beissbarth • B. Michael Ghadimi • Heinz Becker • \\ Torsten Liersch
}

Received: 13 August 2009 / Accepted: 22 September 2009/Published online: 15 October 2009

(C) 2009 The Author(s). This article is published with open access at Springerlink.com

\begin{abstract}
Purpose Preoperative chemoradiotherapy (CRT) is supposed not only to reduce lymph node metastases but also lymph node recovery in rectal cancer specimens. The objective of this prospective study was to determine the effects of chemoradiation on mesorectal lymph node retrieval under terms of a meticulous histopathological evaluation.

Methods Specimens from 64 consecutive patients with stage II/III rectal cancer receiving preoperative 5-FU-based CRT were investigated. All patients were treated within the German Rectal Cancer Trial CAO/ARO/AIO-04. After surgery (including quality assessed total mesorectal excision), extensive pathological diagnostics was performed with embedding and microscopic evaluation of the whole mesorectal soft tissue compartment.

Results A total number of 2,021 lymph nodes were recovered (31.6 per specimen) within pathological work-up. There was no significant correlation between the number of retrieved nodes and patient- as well as tumor-dependent parameters. Lymph node size constantly amounted for less than $0.5 \mathrm{~cm}$. Twenty patients $(31.3 \%)$ had persistent nodal metastases. A considerable incidence of residual micrometastatic involvement in lymph nodes $<0.3 \mathrm{~cm}$ (in $9.4 \%$ of all patients) was detected by extensive pathologic work-up. Conclusion Reliable nodal staging with high numbers of detected nodes was feasible after neoadjuvant CRT. Micrometastases frequently occur in small lymph nodes detected by microscopic evaluation.
\end{abstract}

This work was supported by the Deutsche Forschungsgemeinschaft (KFO 179: Biological basis of individual tumor response in patients with rectal cancer).

T. Sprenger $(\bowtie) \cdot$ K. Homayounfar $\cdot$ B. M. Ghadimi $\cdot$ H. Becker $\cdot$

T. Liersch

Department of General and Visceral Surgery,

University Medical Center Göttingen, Georg-August-University,

Robert-Koch-Str. 40,

37099 Göttingen, Germany

e-mail: tsprenger@chirurgie-goettingen.de

H. Rothe

Department of Pathology, University Medical Center Göttingen,

Robert-Koch-Str. 40,

37099 Göttingen, Germany

\section{T. Beissbarth}

Department of Medical Statistics,

University Medical Center Göttingen,

Robert-Koch-Str. 40,

37099 Göttingen, Germany
Keywords Locally advanced rectal cancer.

Preoperative chemoradiotherapy - Total mesorectal excision . Pathologic diagnostics

\section{Introduction}

Rectal cancer is the second most malignant disease in European countries with an annual incidence of about 70,000 cases. $^{1,2}$ Distinct progress in therapy of rectal cancer has been achieved within the last 15 years by implementation of appropriate surgical techniques such as total mesorectal excision (TME) ${ }^{3}$ and neoadjuvant treatment strategies.

The German Rectal Cancer Study Group has recently demonstrated significant improvements in local control, a higher rate of sphincter preservation, and decreased toxicity by preoperative in contrast to postoperative chemoradio- 
therapy (CRT). A combined neoadjuvant 5-fluorouracil (5FU)-based CRT is thus considered as standard therapy in locally advanced (stage II/III) rectal cancer. ${ }^{4}$ Local recurrence rates were significantly reduced, and in subgroup analyses, a distinct improvement in overall survival was achieved in patients with optimal and good response to applied CRT. ${ }^{5}$

A benefit of a general application of adjuvant chemotherapy in individual patients remains unclear, and advices for detection of patients with higher risk of cancer relapse are imperatively needed. ${ }^{6-9}$ Lymph node status after preoperative CRT has repeatedly been described as a strong prognostic factor in patients with locally advanced rectal cancer. $^{10-12}$

Thus, the evaluation of an accurate nodal status is an essential task for both surgeon and pathologist because significant correlations between the number of retrieved nodes and survival of patients have frequently been demonstrated. ${ }^{12-17}$ Several investigations have been published within the last years showing that preoperative CRT decreases the number of lymph nodes detected in the surgical specimen. ${ }^{18-20}$ Some authors report a consistent remission of lymph nodes below the least number of 12 nodes, recommended by the International Union against Cancer (UICC), or even a complete deletion of lymph nodes in the surgical specimen. ${ }^{21,22}$

We summarize results from 64 consecutive patients with locally advanced rectal cancer from our institution. All patients were participants of the randomized phase III German Rectal Cancer Trial CAO/ARO/AIO-04 and received standardized 5-FU-based long-term CRT, curative surgical resection including TME, and extensive macroscopic and histopathological diagnostics.

The aim of this prospective study was to clarify the effects of preoperative CRT on quantities of lymph nodes within the mesorectal soft tissue compartment. Therefore, we meticulously explored rectal cancer specimens with particular focus on small nodes unlikely to be detected by standard manual lymph node retrieval as predominately performed in the retrospective analyses published in this subject.

\section{Material and Methods}

Sixty-four consecutive patients with resectable stage II/III rectal adenocarcinoma located no more than $12 \mathrm{~cm}$ above the anocutaneous verge and treated within the protocol of the ongoing $\mathrm{CAO} / \mathrm{ARO} / \mathrm{AIO}-04$ trial of the German Rectal Cancer Study Group between October 2006 and September 2008 were analyzed prospectively.

All patients were medicated at the Department of General and Visceral Surgery, University Medical Center Göttingen, Germany.
Rigid rectoscopy with endorectal ultrasound (ERUS), magnetic resonance imaging (MRI) of the pelvis, computed tomography (CT) of the pelvis, abdomen, and thorax were performed to confirm locally advanced tumor stage and to exclude patients with evidence of distant metastases.

Except for one female patient with a squamous cell carcinoma of the larynx more than 20 years earlier, no patient had previous cancer or received cancer-related chemo- or radiotherapy. There were no contraindications to CRT at the time of staging in any patient. The trial was approved by the Ethics Committee of the University of Göttingen.

\section{Treatment}

Sixty-four eligible patients ( 48 male and 16 female) with a median age of 65 years (36-82 years) underwent standardized preoperative CRT with a total irradiation dose of 50.4 Gy (in multiple three and four-field technique, delivered in 28 fractions of $1.8 \mathrm{~Gy}$ ) and a simultaneous 6week course of 5-FU-based chemotherapy.

Radical oncologic surgery was performed 6 weeks after completion of preoperative treatment and actual clinical restaging by experienced colorectal surgeons including quality assessed TME in all cases.

Surgical procedures consisted of 46 (72\%) low anterior resections, 16 (25\%) abdominoperineal resections, and two (3\%) discontinuous resections (Hartmann's procedure).

Immediately after removal of the specimen, a perioperative quality control of TME was performed by a surgeon not involved in the actual surgical intervention.

This procedure consisted of methylene blue injection into the inferior mesenteric artery and revealed smaller surgery-related defects in pelvic fascia and mesorectal surfaces by selective colorant escape.

\section{Macroscopic and Histopathological Evaluation}

After surgical quality control, the specimens were committed to the pathologist for macroscopic examination of mesorectal surfaces according to a quality assessment system based on the MERCURY criteria. ${ }^{23}$ All 64 specimens of this study were completely worked up by the same gastrointestinal pathologist (H. R.).

Histopathological staging was realized according to the tumor-node-metastasis (TNM) classification of the UICC and comprised an evaluation of the circumferential resection margins (CRM) concerning tumor distance of $\leq 1 \mathrm{~mm}$ or tumor perforation. ${ }^{24}$

The macroscopic work-up procedure consisted of a ventral longitudinal opening of the specimen along the rectal lumen excluding the tumor region and a fixation of the draft-free needle-fixed specimen for at least $72 \mathrm{~h}$ in $5 \%$ formalin solution. 
After fixation and colorant inking of the mesorectal surface, the specimen was cut in consecutive transversal 5$\mathrm{mm}$ sectional slices, beginning at the distal resection margin and comprising the region proximally of the tumor at least up to the lateral vessel branching of the inferior mesenteric artery.

The cross-sectional slices were re-divided into $2.5-\mathrm{mm}$ slices and completely paraffin embedded. Beside ypTNM staging with assessment of the proximal, distal, and circumferential resection margins, it was thus possible to detect structures of microscopic dimension including any residual tumor manifestation, i.e., very small and atrophic lymph nodes below $0.1 \mathrm{~cm}$ in diameter with or without micrometastases and isolated tumor cells, intra- or extramural vascular and perineural invasion and mesorectal tumor cell foci, which were presumably left behind after CRT.

Within this procedure, fat clearance methods for detecting lymph nodes were not used as the mesorectal soft tissue was embedded completely.

Additionally, irradiation-induced tumor regression was denoted on the basis of a semi-quantitative five-point grading system according to established methods. ${ }^{25,26}$

\section{Microscopic Lymph Node Evaluation and Count}

In order to evaluate the entire mesorectal soft tissue compartment for available lymph nodes after preoperative CRT, a complete paraffin-embedding of the rectal specimens has been implemented. As unencapsulated lymphoid aggregates with follicles are verifiable in pericolic and perirectal tissue, histopathological criteria of a lymph node have been defined prospectively. Only entirely encapsulated lymphatic tissue with marginal sinus and at least residual lymph follicles were-independently of size - counted as lymph node. To prevent double-sectioning of individualparticularly smaller $(<2.5 \mathrm{~mm})$ - nodes two optimal section levels from each tissue block were examined consecutively after cutting the block.

A median number of 147 standard sized tissue blocks were examined per case (range, 119-213). Including 3 days of formalin fixation, the median turn-around time from surgical excision of the specimen to completion of final diagnosis was 6 days.

\section{Statistical Analysis}

Correlations between numbers of detected mesorectal lymph nodes and various patient- and tumor-related clinicopathological findings were assessed by the function cor. test of the statistical software R (version 2.8; www.rproject.org).

The significance level was set to $\alpha=5 \%$ for all tests.

\section{Results}

Sixty-four surgical specimens with low and mid-third rectal cancers (located within $12 \mathrm{~cm}$ from anal verge) were investigated. Average tumor size (longitudinal dimension) after treatment was $2.51 \mathrm{~cm}(0-8 \mathrm{~cm}$; median, $2.5 \mathrm{~cm})$, and average tumor level was $6.4 \mathrm{~cm}$ from anal verge $(0-12 \mathrm{~cm}$; median, $6.0 \mathrm{~cm}$ ). Thirty tumors were located in the lower third of the rectum $(0-6 \mathrm{~cm}), 34$ were positioned in the mid-third $(6-12 \mathrm{~cm})$.

A histopathologically confirmed complete resection (R0 status) of proximal and distal resection margins was achieved in all cases. Circumferential resection margins (CRM) were free of vital tumor cells with a minimum distance of $\geq 1 \mathrm{~mm}$ in each specimen. Seven patients $(11.7 \%)$ with no evidence of distant metastatic disease in pretherapeutic CT scans presented with liver (six cases; detected by intraoperative ultrasound) and peritoneal (one case) metastases at the time of surgery. Due to their consistent small size, the liver metastases might represent systemic tumor progression during preoperative treatment as well as misdiagnosis in initial clinical staging (Table 1).

Tumor regression parameters became apparent by T-level downsizing (comparing cT and ypT) in 25 patients (39\%). Tlevel was decreased by one level in 11 patients $(17.1 \%)$ and by two or three levels in seven patients each (10.9\%).

UICC downstaging (comparing cUICC and ypUICC) was performed in 36 patients $(56.3 \%)$. In 18 patients (28.1\%), the tumor stage was reduced by one, 11 patients $(17.1 \%)$ were downstaged by two, and finally, seven patients $(10.9 \%)$ were downstaged by three stages.

Tumor regression grading resulted in three patients (4.6\%) with low tumor regression (TRG 1). Fifty-three patients $(82.8 \%$ ) had intermediate regression (TRG 2+3), and eight patients $(12.5 \%)$ presented with pathological complete regression of the primary tumor (TRG 4).

Pathological quality assessment was performed according to modified MERCURY criteria $^{23}$ respecting surgical standard of our institution and resulted in the following findings.

Thirty-six specimens (56.3\%) showed optimal quality of TME with no defects and smooth surfaces (grade 1). In 21 cases $(32.8 \%)$, postsurgical mesorectal integrity was given but with very little irregularities of the mesorectal surfaces (grade 2), and seven (10.9\%) specimens underwent TME with focal defects and lacerations of mesorectal soft tissue but, in all cases, without visible muscularis propria (grade 3).

An intra- or extramural vascular invasion was identified in nine patients (14.1\%). Perineural invasion appeared with considerable frequency in 24 patients $(37.5 \%)$ after preoperative CRT (Table 2).

A total number of 2,021 lymph nodes were recovered (mean, 31.6 nodes per patient; range, 12-81; median, 30.0). Twenty patients (31.3\%) had persistent nodal metastases in 
Table 1 Clinicopathological Findings

\begin{tabular}{|c|c|c|c|}
\hline Findings & Feature & $\begin{array}{l}\text { Number of Patients } \\
n=64\end{array}$ & Percent \\
\hline & \multicolumn{3}{|l|}{ Gender } \\
\hline & Male & 48 & 75 \\
\hline & Female & 16 & 25 \\
\hline & \multicolumn{3}{|l|}{ Age (years) } \\
\hline & Median & 65 & \\
\hline & Range & $36-82$ & \\
\hline & \multicolumn{3}{|l|}{ Tumor Distance from Anal Verge $(\mathrm{cm})$} \\
\hline & $0-6$ & 30 & 47 \\
\hline & $>6-12$ & 34 & 53 \\
\hline & \multicolumn{3}{|l|}{ cT stage } \\
\hline & 1 & 0 & 0 \\
\hline & 2 & $2 *$ & 3 \\
\hline & 3 & 60 & 94 \\
\hline & 4 & 2 & 3 \\
\hline & \multicolumn{3}{|l|}{ cN Stage } \\
\hline & Positive & 51 & 80 \\
\hline & Negative & 13 & 20 \\
\hline & \multicolumn{3}{|l|}{ cUICC Stage } \\
\hline & I & 0 & 0 \\
\hline & II & 13 & 20 \\
\hline & III & 51 & 80 \\
\hline & IV & 0 & 0 \\
\hline & \multicolumn{3}{|l|}{ Neoadjuvant treatment } \\
\hline & $50.4 \mathrm{~Gy}+$ standard 5-FU & 34 & 53 \\
\hline & 50.4 Gy + intensified 5-FU/oxaliplatin & 30 & 47 \\
\hline & \multicolumn{3}{|l|}{ Surgical procedure (including TME) } \\
\hline & Low anterior resection & 46 & 72 \\
\hline & Abdominoperineal resection & 16 & 25 \\
\hline & Hartmann's procedure & 2 & 3 \\
\hline & \multicolumn{3}{|l|}{ Resection status } \\
\hline & $\mathrm{R} 0$ & 64 & 100 \\
\hline & $\mathrm{R} 1$ & 0 & 0 \\
\hline & \multicolumn{3}{|l|}{ Circumferential resection margin (CRM) } \\
\hline & Negative & 64 & 100 \\
\hline & Positive & 0 & 0 \\
\hline & \multicolumn{3}{|l|}{ TME quality (modified Mercury criteria) } \\
\hline & 1 Optimal & 36 & 56 \\
\hline & 2 Good & 21 & 33 \\
\hline Patients had uN+ status accord- & 3 Moderate & 7 & 11 \\
\hline
\end{tabular}

Patients had $\mathrm{uN}+$ status according cUICC III cumulative 53 lymph nodes. The mean number of involved nodes was 2.65 per patient (range, 1-8 nodes; median, 1.0). Among these 53 lymph node metastases, 15 manifested as micrometastases (not larger than $0.2 \mathrm{~cm}$ ). Three additional patients $(4.6 \%)$ showed evidence of isolated tumor cells (ITC, not larger than $0.02 \mathrm{~cm}$ ) in one lymph node each. According to the current TNM classification, the latter were classified as "ypN0" or "ypN0 (i+)" respectively, charac- terizing ITC as cells without yet known specific metastatic attributes. $^{27}$

Lymph node size including non-metastatic and metastatic nodes was below $0.5 \mathrm{~cm}$ in all but one case. The majority of nodes ranged between 0.1 and $0.2 \mathrm{~cm}$.

One exceptional patient with mucinous differentiated adenocarcinoma had lymph nodes ranging from 0.5 to $1 \mathrm{~cm}$ without viable tumor cells but, instead, large mucinous 
lakes, indicating complete regression of previous tumor infiltration.

The detected mesorectal lymph nodes were unequally distributed over the specimen.

The majority of 1,395 nodes $(69 \%)$ were located proximally to the tumor region along the trunk of the superior rectal artery within the upper radiation field.

Four hundred forty-nine nodes $(22 \%)$ were located within the tumor region and therewith in the central radiation field, and finally, $177(9 \%)$ nodes could be detected in the mesorectal tissue below the tumor region and in the lower radiation field.

There was no significant correlation between the numbers of detected mesorectal lymph nodes and patientdependent variables (gender and age). Tumor-related variables (tumor size, ypTNM status, number of lymph node metastases, histopathological tumor regression grade, tumor differentiation, lymph and blood vessel invasion, and perineural invasion) did also not affect the number of available lymph nodes within the perirectal tissue (Table 3).

Due to the reduced lymph node size after preoperative CRT, micrometastases $(<0.2 \mathrm{~cm})$ accounted for $28.3 \%$ of all lymph node metastases. In detail, $30 \%$ of ypN + patients had exclusive micrometastatic involvement. Based on the total study population, the proportion of patients with solely micrometastases was $9.4 \%$ after CRT.

Under terms of extensive pathological work-up and microscopic evaluation of the entire mesorectum, higher numbers of identified lymph nodes per specimen were not correlated with increased detection of nodal metastases. The 44 patients without nodal involvement had a median number of 30 detected nodes, whereas patients with lymph node metastases had 29.5 nodes. Interestingly, in patients with solely micrometastatic involvement, the median retrieval accounted for only 24.5 nodes.

In pretherapeutic staging (ERUS, CT, and MRI), 13 patients $(20.3 \%)$ turned out to have no evidence of mesorectal lymph node metastases (clinical stage II). In pathological staging, altogether, four (31\%) of 13 patients with previous (clinical) stage II actually had ypN+ status comprising four micrometastases in a single lymph node each, indicating the potential incertitude of pretherapeutic nodal staging.

\section{Discussion}

Lymph node status is currently the strongest prognostic factor in rectal cancer after neoadjuvant CRT. A valid statement concerning nodal involvement is of outstanding importance for individual prognosis and further treatment strategies of patients with locally advanced rectal cancer. Reliable nodal staging of colorectal cancer requires a
Table 2 Post-therapeutic Parameters

\begin{tabular}{|c|c|c|}
\hline Feature & $\begin{array}{l}\text { Number of patients } \\
n=64\end{array}$ & Percent* \\
\hline \multicolumn{3}{|c|}{ Tumor size $(\mathrm{cm})$} \\
\hline Median & 2.5 & \\
\hline Range & $0-8$ & \\
\hline \multicolumn{3}{|c|}{ Vascular invasion } \\
\hline Yes & 9 & 14 \\
\hline No & 55 & 86 \\
\hline \multicolumn{3}{|c|}{ Perineural Invasion } \\
\hline Yes & 24 & 38 \\
\hline No & 40 & 62 \\
\hline \multicolumn{3}{|c|}{ Tumor regression grading } \\
\hline 0 & 0 & 0 \\
\hline 1 & 3 & 5 \\
\hline 2 & 20 & 31 \\
\hline 3 & 33 & 52 \\
\hline 4 & 8 & 13 \\
\hline \multicolumn{3}{|l|}{ ypT stage } \\
\hline 0 & 8 & 13 \\
\hline 1 & 7 & 11 \\
\hline 2 & 9 & 14 \\
\hline 3 & 36 & 56 \\
\hline 4 & 4 & 6 \\
\hline \multicolumn{3}{|l|}{ ypN stage } \\
\hline 0 & 44 & 69 \\
\hline 1 & 15 & 23 \\
\hline 2 & 5 & 8 \\
\hline \multicolumn{3}{|l|}{ ypM stage } \\
\hline 0 & 57 & 89 \\
\hline 1 & 7 & 11 \\
\hline \multicolumn{3}{|c|}{ ypUICC stage } \\
\hline 0 & 8 & 13 \\
\hline I & 12 & 19 \\
\hline II & 21 & 33 \\
\hline III & 16 & 25 \\
\hline IV & 7 & 11 \\
\hline \multicolumn{3}{|c|}{ T-level downsizing } \\
\hline Yes & 25 & 39 \\
\hline No & 39 & 61 \\
\hline \multicolumn{3}{|c|}{ UICC-downstaging } \\
\hline Yes & 36 & 56 \\
\hline No & 28 & 44 \\
\hline
\end{tabular}

certain number of detected and evaluated nodes and - as a guideline, not as a precondition-lymphadenectomy should ordinarily include 12 regional lymph nodes to validate $\mathrm{pN} 0$ status. ${ }^{27}$ There are no particular recommendations concerning effective lymph node retrieval in rectal cancer specimens after preoperative CRT (ypN status) yet. Several 
Table 3 Correlations Between Lymph Node Numbers and Different Variables

\begin{tabular}{lccc}
\hline Variable & Correlation & $95 \%$ Confidence Interval & $p$ value \\
\hline Gender & -0.11 & $-0.34 ; 0.12$ & 0.34 \\
Age & -0.2 & $-0.41 ; 0.04$ & 0.098 \\
Surgical procedure & 0.2 & $-0.03 ; 0.42$ & 0.085 \\
Tumor level & 0.1 & $-0.13 ; 0.33$ & 0.38 \\
Tumor size & 0.04 & $-0.2 ; 0.27$ & 0.76 \\
ypT & -0.2 & $-0.41 ; 0.04$ & 0.098 \\
ypN & 0 & $-0.23 ; 0.23$ & 0.99 \\
ypM & -0.08 & $-0.3 ; 0.16$ & 0.52 \\
No. of nodal metastases & 0.02 & $-0.21 ; 0.25$ & 0.85 \\
Tumor grading & -0.2 & $-0.41 ; 0.03$ & 0.089 \\
Blood vessel invasion & 0.07 & $-0.17 ; 0.29$ & 0.59 \\
Lymph vessel invasion & 0.07 & $-0.16 ; 0.3$ & 0.55 \\
Perineural invasion & -0.12 & $-0.34 ; 0.12$ & 0.32 \\
\hline
\end{tabular}

studies independently investigated the number of retrieved lymph nodes in patients being treated with combined longterm CRT and showed a continuous decrease in the number of lymph nodes compared to non-irradiated specimens. Mean numbers of detected nodes varied between 4 and 14 per specimen. ${ }^{18-20,28}$ In our prospectively evaluated collective with standardized preoperative and surgical treatment as well as pathological procedures, a mean number of 31.6 nodes were recovered per specimen.

Interpreting our results, we cannot disprove the assumption that preoperative long-term CRT reduces the cumulative number of lymph nodes within the rectal specimen, although we detected surpassingly more mesorectal nodes than any other investigation even without preoperatively applied CRT. $^{10,13,18,19,21,29}$

This might be rationalized for one thing by standardized and quality-controlled surgery and a high rate of optimally performed TME within this study. The removal of the entire mesorectal soft tissue compartment within its intact envelope fascia not only ensures minimal local recurrence rates and functional preservation of pelvic structures but also guaranties a complete regional lymphadenctomy. Moreover, optimized and extensive macro- and histopathological diagnostic procedures are responsible for the detection of more than an allegedly representative number of lymph nodes from a rectal cancer specimen.

Under the terms of an extensive pathological work-up, the rationale of nodal staging within this investigation has been altered from evaluating a representative consensusagreed number of mesorectal nodes to evaluating the (near-) total number of available rectal lymph nodes.

A significant reduction of lymph node count in rectal cancer specimens has been reported after long-term radiation (doses ranging from 45 to $50.4 \mathrm{~Gy}$ ) with different concomitant chemotherapy regimes ${ }^{18-20,22,30}$ as well as after short-term radiotherapy. ${ }^{31,32}$ Only one single investiga- tion did not find significant differences of mesorectal lymph node retrieval in patients after neoadjuvant treatment compared to patients who underwent primary surgical treatment. However, in this study, altogether, only $17 \%$ of the study population had neoadjuvant therapy comprising both longterm 5-FU-based CRT as well as short-term radiation. ${ }^{29}$

Perez et al. evaluated rectal specimens from 18 cadavers without evidence of colorectal disease regarding number and distribution of mesorectal lymph nodes. They found a mean number of 5.7 nodes per specimen and concluded that the absence of pathological alterations within the rectum might cause lower lymph node count in contrast to other investigations. $^{33}$

Anyway, concerning mesorectal lymph node numbers, we did not find any correlation neither with patient-related factors like gender and age nor tumor-related pathological characteristics like individual stage or therapy-induced tumor regression.

Additionally, our investigation indicates that neoadjuvant CRT appears to have an important effect on mesorectal lymph node size. We noticed that the majority of nodes varied between 0.1 and $0.2 \mathrm{~cm}$, which we consider to be a consequence of applied CRT, in accordance with others who also described a significant reduction of nodal size. $^{32,34,35}$ Changes in morphology and function after radiation of lymph nodes have also been described with decreased numbers of CD4+ lymphocytes and dendritic cells in paracortical areas of the irradiated nodes. This might implicate a reduced immune and tumor suppressive function as well as reduced mechanical filter function for tumor cells. ${ }^{36,37}$

It appears to us that radiation-related reduction of lymph node size might be the main reason for a reputedly reduction of lymph node numbers in irradiated specimens worked up with conventional (manual) retrieval because of the apparent difficulty to detect lymph nodes smaller than $0.2 \mathrm{~cm}$. 
Murphy et al $^{38}$ recognized lymph node size as an independent prognostic indicator for survival in nodenegative rectal cancers after primary surgery. They supposed small nodes, measuring $<2 \mathrm{~mm}$ less likely to be infiltrated and suggest a consideration of lymph node size within the staging systems for rectal cancer.

As opposed to this, in $31 \%$ of our patients, lymph node metastases have been detected, among these, 15 micrometastases (28.3\%) in lymph nodes with constantly $<0.3 \mathrm{~cm}$. Regarding other investigations using immunohistochemistry to determine occult lymph node micrometastases in stage II rectal cancers after neoadjuvant CRT, there is a comparatively high incidence of micrometastases detected with conventionally hematoxylin-eosin staining in our collective. ${ }^{39}$

Although their prognostic role has not been clarified, finally, we consider them as important findings, which need to be investigated further on to reveal individual tumor biology and distant metastatic potential. We suppose an appreciable number of mesorectal micrometastases in lymph nodes below $0.5 \mathrm{~cm}$ not being detected by manual lymph node recovery and standard pathological diagnostics.

Concerning the minimum number of lymph nodes needed to stage patients with locally advanced rectal cancer, statistical analyses indicated that the probability of detecting a single lymph node metastasis increases with the number of retrieved nodes and amounts to $46 \%$ when 18 nodes have been recovered. ${ }^{40}$ This resulted in the recommendation of finding smaller nodes ranging from 0.1 or $0.2 \mathrm{~cm}$ in diameter. Nevertheless, other investigations revealed that more than $60 \%$ of institutions in the USA fail to generally achieve the controversial benchmark of 12 lymph nodes per specimen. ${ }^{41}$

Extensive pathological diagnostics with microscopic evaluation of the entire lymph node containing mesorectal compartment leads to obvious higher lymph node recovery after preoperative CRT than conventional pathological work-up. This has distinct clinical implications because several investigations have shown the prognostic relevance of enhanced lymph node retrieval in stage II colorectal and rectal cancer patients. ${ }^{13-15} \mathrm{Kim}$ et al., who reported the results of 900 node negative rectal cancer patients, postulated a minimum number of 23 evaluated nodes to stratify patients for low and high risk of cancer-specific survival. ${ }^{42}$ As nodal status-particularly after preoperative CRT - is a major decision criterion for the need of adjuvant treatment, it should be based on a stable diagnostic fundament. ${ }^{43}$

We are very well aware that the meticulous lymph node evaluation in our study is hardly convertible in pathological routine diagnostics in rectal cancer specimens. However, it shows that adequate nodal staging is feasible after applied CRT with consequently more than the consensual number of 12 nodes per specimen. In summary, reliable lymph node recovery emphasizes the role of the surgeon and especially of the pathologist. Their role exceeds patient- and therapydependent factors by far. These results of our evaluation are supported by another large prospective investigation on more than 7,000 colorectal specimens. ${ }^{44}$

In conclusion, our study reveals that the diligence and accuracy of the pathologist - beside the surgeons obligation to supply high-quality TME specimens-is essential for sufficient lymph node retrieval and valid nodal staging after preoperative RCT.

Open Access This article is distributed under the terms of the Creative Commons Attribution Noncommercial License which permits any noncommercial use, distribution, and reproduction in any medium, provided the original author(s) and source are credited.

\section{References}

1. Landis SH, Murray T, Bolden S, Wingo PA. Cancer statistics, 1998. CA Cancer J Clin 1998;48:6-29.

2. Midgley R, Kerr D. Colorectal cancer. Lancet 1999;353:391-399.

3. Enker WE, Thaler HT, Cranor ML, Polyak T. Total mesorectal excision in the operative treatment of carcinoma of the rectum. J Am Coll Surg 1995;181:335-346.

4. Sauer R, Becker H, Hohenberger W, Rodel C, Wittekind C, Fietkau R, Martus P, Tschmelitsch J, Hager E, Hess CF, Karstens JH, Liersch T, Schmidberger H, Raab R. Preoperative versus postoperative chemoradiotherapy for rectal cancer. N Engl J Med 2004;351:1731-1740.

5. Rodel C, Liersch T, Hermann RM, Arnold D, Reese T, Hipp M, Furst A, Schwella N, Bieker M, Hellmich G, Ewald H, Haier J, Lordick F, Flentje M, Sulberg H, Hohenberger W, Sauer R. Multicenter phase II trial of chemoradiation with oxaliplatin for rectal cancer. J Clin Oncol 2007;25:110-117.

6. Andre T, Boni C, Mounedji-Boudiaf L, Navarro M, Tabernero J, Hickish T, Topham C, Zaninelli M, Clingan P, Bridgewater J, Tabah-Fisch I, de Gramont A. Oxaliplatin, fluorouracil, and leucovorin as adjuvant treatment for colon cancer. N Engl J Med 2004;350:2343-2351.

7. Collette L, Bosset JF, den Dulk M, Nguyen F, Mineur L, Maingon P, Radosevic-Jelic L, Pierart M, Calais G. Patients with curative resection of cT3-4 rectal cancer after preoperative radiotherapy or radiochemotherapy: does anybody benefit from adjuvant fluorouracil-based chemotherapy? A trial of the European Organisation for Research and Treatment of Cancer Radiation Oncology Group. J Clin Oncol 2007;25:4379- 4386.

8. Minsky BD. Adjuvant management of rectal cancer: the more we learn, the less we know. J Clin Oncol 2007;25:4339-4340.

9. Quasar Collaborative G, Gray R, Barnwell J, McConkey C, Hills RK, Williams NS, Kerr DJ. Adjuvant chemotherapy versus observation in patients with colorectal cancer: a randomised study. Lancet 2007;370:2020-2029.

10. Leibold T, Shia J, Ruo L, Minsky BD, Akhurst T, Gollub MJ, Ginsberg MS, Larson S, Riedel E, Wong WD, Guillem JG. Prognostic implications of the distribution of lymph node metastases in rectal cancer after neoadjuvant chemoradiotherapy. J Clin Oncol 2008;26:2106-2111.

11. Liersch T, Langer C, Ghadimi BM, Kulle B, Aust DE, Baretton GB, Schwabe W, Hausler P, Becker H, Jakob C. Lymph node 
status and TS gene expression are prognostic markers in stage II/ III rectal cancer after neoadjuvant fluorouracil-based chemoradiotherapy. J Clin Oncol 2006;24:4062-4068.

12. Sarli L, Bader G, Iusco D, Salvemini C, Mauro DD, Mazzeo A, Regina G, Roncoroni L. Number of lymph nodes examined and prognosis of TNM stage II colorectal cancer. Eur J Cancer 2005;41:272-279.

13. Caplin S, Cerottini JP, Bosman FT, Constanda MT, Givel JC. For patients with Dukes' B (TNM Stage II) colorectal carcinoma, examination of six or fewer lymph nodes is related to poor prognosis. Cancer 1998;83:666-672.

14. Cianchi F, Palomba A, Boddi V, Messerini L, Pucciani F, Perigli G, Bechi P, Cortesini C. Lymph node recovery from colorectal tumor specimens: recommendation for a minimum number of lymph nodes to be examined. World J Surg 2002;26:384-389.

15. Luna-Perez P, Rodriguez-Ramirez S, Alvarado I, Gutierrez de la Barrera M, Labastida S. Prognostic significance of retrieved lymph nodes per specimen in resected rectal adenocarcinoma after preoperative chemoradiation therapy. Arch Med Res 2003;34:281-286.

16. Tepper JE, O’Connell MJ, Niedzwiecki D, Hollis D, Compton C, Benson AB 3rd, Cummings B, Gunderson L, Macdonald JS, Mayer RJ. Impact of number of nodes retrieved on outcome in patients with rectal cancer. J Clin Oncol 2001;19:157-163.

17. Tsai HL, Lu CY, Hsieh JS, Wu DC, Jan CM, Chai CY, Chu KS, Chan HM, Wang JY. The prognostic significance of total lymph node harvest in patients with T2-4N0M0 colorectal cancer. J Gastrointest Surg 2007;11:660-665.

18. Wichmann MW, Muller C, Meyer G, Strauss T, Hornung HM, Lau-Werner U, Angele MK, Schildberg FW. Effect of preoperative radiochemotherapy on lymph node retrieval after resection of rectal cancer. Arch Surg 2002;137:206-210.

19. Wijesuriya RE, Deen KI, Hewavisenthi J, Balawardana J, Perera M. Neoadjuvant therapy for rectal cancer down-stages the tumor but reduces lymph node harvest significantly. Surg Today 2005;35:442-445.

20. de la Fuente SG, Manson RJ, Ludwig KA, Mantyh CR. Neoadjuvant chemoradiation for rectal cancer reduces lymph node harvest in proctectomy specimens. J Gastrointest Surg 2009;13:269-274.

21. Baxter NN, Morris AM, Rothenberger DA, Tepper JE. Impact of preoperative radiation for rectal cancer on subsequent lymph node evaluation: a population-based analysis. Int J Radiat Oncol Biol Phys 2005;61:426-431.

22. Habr-Gama A, Perez RO, Proscurshim I, Rawet V, Pereira DD, Sousa AH, Kiss D, Cecconello I. Absence of lymph nodes in the resected specimen after radical surgery for distal rectal cancer and neoadjuvant chemoradiation therapy: what does it mean? Dis Colon Rectum 2008;51:277-283.

23. Nagtegaal ID, van de Velde CJ, van der Worp E, Kapiteijn E, Quirke P, van Krieken JH. Macroscopic evaluation of rectal cancer resection specimen: clinical significance of the pathologist in quality control. J Clin Oncol 2002;20:1729-1734.

24. Sobin LH. TNM, sixth edition: new developments in general concepts and rules. Semin Surg Oncol 2003;21:19-22.

25. Dworak O, Keilholz L, Hoffmann A. Pathological features of rectal cancer after preoperative radiochemotherapy. Int J Colorectal Dis 1997;12:19-23.

26. Wittekind C, Tannapfel A. Regression grading of colorectal carcinoma after preoperative radiochemotherapy. An inventory. Pathologe 2003;24:61-65.

27. Sobin LH. TNM classification: clarification of number of regional lymph nodes for pN0. Br J Cancer 2001;85:780.

28. Rinkus KM, Russell GB, Levine EA. Prognostic significance of nodal disease following preoperative radiation for rectal adenocarcinoma. Am Surg 2002;68:482-487.
29. Thorn CC, Woodcock NP, Scott N, Verbeke C, Scott SB, Ambrose NS. What factors affect lymph node yield in surgery for rectal cancer? Colorectal Dis 2004;6:356-361.

30. Sermier A, Gervaz P, Egger JF, Dao M, Allal AS, Bonet M, Morel $\mathrm{P}$. Lymph node retrieval in abdominoperineal surgical specimen is radiation time-dependent. World J Surg Oncol 2006;4:29.

31. Kapiteijn E, Marijnen CA, Nagtegaal ID, Putter H, Steup WH, Wiggers T, Rutten HJ, Pahlman L, Glimelius B, van Krieken JH, Leer JW, van de Velde CJ. Preoperative radiotherapy combined with total mesorectal excision for resectable rectal cancer. N Engl J Med 2001;345:638-646.

32. Marijnen CA, Nagtegaal ID, Klein Kranenbarg E, Hermans J, van de Velde CJ, Leer JW, van Krieken JH. No downstaging after short-term preoperative radiotherapy in rectal cancer patients. J Clin Oncol 2001;19:1976-1984.

33. Perez RO, Seid VE, Bresciani EH, Bresciani C, Proscurshim I, Pereira DD, Kruglensky D, Rawet V, Habr-Gama A, Kiss D. Distribution of lymph nodes in the mesorectum: how deep is TME necessary? Tech Coloproctol 2008;12:39-43.

34. Koh DM, Chau I, Tait D, Wotherspoon A, Cunningham D, Brown G. Evaluating mesorectal lymph nodes in rectal cancer before and after neoadjuvant chemoradiation using thin-section T2-weighted magnetic resonance imaging. Int $\mathrm{J}$ Radiat Oncol Biol Phys 2008;71:456-461.

35. Perez RO, Pereira DD, Proscurshim I, Gama-Rodrigues J, Rawet V, Sao Juliao GP, Kiss D, Cecconello I, Habr-Gama A. Lymph node size in rectal cancer following neoadjuvant chemoradiationcan we rely on radiologic nodal staging after chemoradiation? Dis Colon Rectum 2009;52:1278-1284.

36. Fajardo LF. Effects of ionizing radiation on lymph nodes. A review. Front Radiat Ther Oncol 1994;28:37-45.

37. Prall F, Wohlke M, Klautke G, Schiffmann L, Fietkau R, Barten M. Tumour regression and mesorectal lymph node changes after intensified neoadjuvant chemoradiation for carcinoma of the rectum. Apmis 2006;114:201-210.

38. Murphy J, Pocard M, Jass JR, O'Sullivan GC, Lee G, Talbot IC. Number and size of lymph nodes recovered from dukes B rectal cancers: correlation with prognosis and histologic antitumor immune response. Dis Colon Rectum 2007;50:1526-1534.

39. Perez RO, Habr-Gama A, Nishida Arazawa ST, Rawet V, Coelho Siqueira SA, Kiss DR, Gama-Rodrigues JJ. Lymph node micrometastasis in stage II distal rectal cancer following neoadjuvant chemoradiation therapy. Int $\mathrm{J}$ Colorectal Dis 2005;20:434-439.

40. Goldstein NS. Lymph node recoveries from 2427 pT3 colorectal resection specimens spanning 45 years: recommendations for a minimum number of recovered lymph nodes based on predictive probabilities. Am J Surg Pathol 2002;26:179-189.

41. Bilimoria KY, Bentrem DJ, Stewart AK, Talamonti MS, Winchester DP, Russell TR, Ko CY. Lymph node evaluation as a colon cancer quality measure: a national hospital report card. J Natl Cancer Inst 2008;100:1310-1317.

42. Kim YW, Kim NK, Min BS, Lee KY, Sohn SK, Cho CH. The influence of the number of retrieved lymph nodes on staging and survival in patients with stage II and III rectal cancer undergoing tumor-specific mesorectal excision. Ann Surg 2009;249:965-972.

43. Chang GJ, Rodriguez-Bigas MA, Eng C, Skibber JM. Lymph node status after neoadjuvant radiotherapy for rectal cancer is a biologic predictor of outcome. Cancer 2009. doi:10.1002/ cncr.24622.

44. Morris EJ, Maughan NJ, Forman D, Quirke P. Identifying stage III colorectal cancer patients: the influence of the patient, surgeon, and pathologist. J Clin Oncol 2007;25:2573-2579. 